\title{
Rupture of a Giant Caesarean Scar Endometriosis Nodule - A Case Report and Literature Review
}

\author{
Arora $\mathrm{BK}^{*}$
}

Department of Surgery, Pt BD Sharma PGIMS, University of Health Sciences, Rohtak, India

*Corresponding author: Arora BK, Professor, Department of Surgery, Pt BD Sharma PGIMS, University of Health Sciences, Rohtak, India 124001, Tel: +91 9466290707, E-mail: drbhavinderarora@gmail.com

Citation: Arora BK (2017) Rupture of a Giant Caesarean Scar Endometriosis Nodule - A Case Report and Literature Review. J Case Rep Stud 5(1): 101. doi: 10.15744/2348-9820.5.101

Received Date: December 20, 2016 Accepted Date: February 24, 2017 Published Date: February 27, 2017

\begin{abstract}
Background: Abdominal wall endometriosis is a rare condition occurring after caesarean section. A small painful nodule or lump near post caesarean scar is the common presentation. Large size endometrial nodules in anterior abdominal wall are uncommon and bleeding is very rare complication.

Case report: In a thirty two years female a giant size endometrial nodule developed in a post caesarean scar. This patient presented as emergency during menstruation because of pain and lump with bluish discolouration. This case is reported for post caesarean scar large size endometriosis with extravasation of blood in surrounding anterior abdominal wall. This giant size endometriosis in anterior abdominal wall involving rectus abdominis muscle was successfully excised with a margin. The residual large size defect was repaired using polypropylene mesh.
\end{abstract}

Conclusion: The complication of rupture and haemorrhage into surrounding tissue is very rare as compared to pelvic endometriosis. The large size endometrial nodule should be treated by excision with a margin.

Keywords: Rupture; Giant; Endometriosis; Caesarean Scar; Abdominal Wall

List of Abbreviations: CT: Computed Tomography; MRI: Magnetic Resonance Imaging; PET: Positron Emission Tomography

\section{Introduction}

Endometriosis is the presence and growth of endometrial tissue outside the uterine cavity. Endometriosis affects 5-10\% of all women in the reproductive age group. The pelvic endometriosis presents with severe pain and infertility. The extrapelvic endometriosis can occur in kidney, urinary bladder, Intestine, omentum, lymph nodes, lungs, extremities, umbilicus and abdominal wall [1].

The anterior abdominal wall is the most common site of extrapelvic endometriosis commonly occurring after caesarean section. This grows to form a lump in the anterior abdominal wall. The common presentation of endometrioma is a painful nodule with a cyclical or non-cyclical pain [2]. This endometriosis nodule is commonly small in size about $3 \mathrm{~cm}$ in most cases [3]. The incidence of anterior abdominal wall endometrioma is rising because more caesarean sections are performed these days. This lump consists of functional endometrial glands and stroma. This functional endometrial tissue is hormone sensitive and increases in size during menstruation. The cyclical correlation can lead to increase in size and can acquire a large size. Giant endometrioma in post caesarean scar is of rare occurrence in anterior abdominal wall [4]. The pelvic endometriosis may undergo complications like bleeding or rupture, inflammation, fibrosis and adhesion presenting as pain in lower abdomen [5]. Because of the functional nature of endometrial glands these complication can occur in abdominal wall endometrioma also. The complication of bleeding and extravasation of blood into surrounding tissue in abdominal wall endometriosis during menstruation has not been described in literature. The ecchymosis due to extravasation of blood can present a diagnostic dilemma. Such ecchymosis in lower abdomen can be present in rectus muscle haematoma due to inferior epigastric tear. Desmoid tumour should also be considered in the differential diagnosis [6]. Occasional case reports in literature are available about umbilical endometriosis in a patient without abdominal wall scar [7]. The radiological studies like ultrasonography, CT scan and MRI are very useful in providing the accurate diagnosis [8]. These radiological studies can easily differentiate abdominal wall endometriosis from other entities. Fine needle aspiration can give tissue diagnosis. Surgical excision with margin of safety is the treatment of choice. This wide excision leads to larger defects which need to be covered with polypropylene mesh [9]. This case report is published because of rare complication of bleeding occurring in a post caesarean scar giant abdominal wall endometriosis. 


\section{Case report}

A case of thirty two years female presenting with a lump in left iliac region with bluish discoloration presented in the outpatient department (Figure 1). She was having two children. Youngest child was 9 years old born by a caesarean section. A small nodule has formed on the left side of caesarean scar for last 8 years. The nodule was painful and became more painful during the menstruation. The excessive cyclical pain was partially relieved by taking nonsteroidal anti-inflammatory drugs. No hormone therapy was used by the patient. This small nodule has been slowly increasing in size and has reached the present size. The bluish discoloration over the lump was present for last two days only and coincided with onset of menstruation. There was no history of trauma or lifting of heavy weight. The lump has increased in size and was extremely painful. On clinical examination there was an indurated tender lump of size 10x11 cm on left side of abdomen. The lump was firm in consistency with restricted mobility. The ultrasound revealed a well-defined mass (Figure 2). CT scan shows a well-defined mass with extravasation of blood into surrounding tissue (Figure 3).

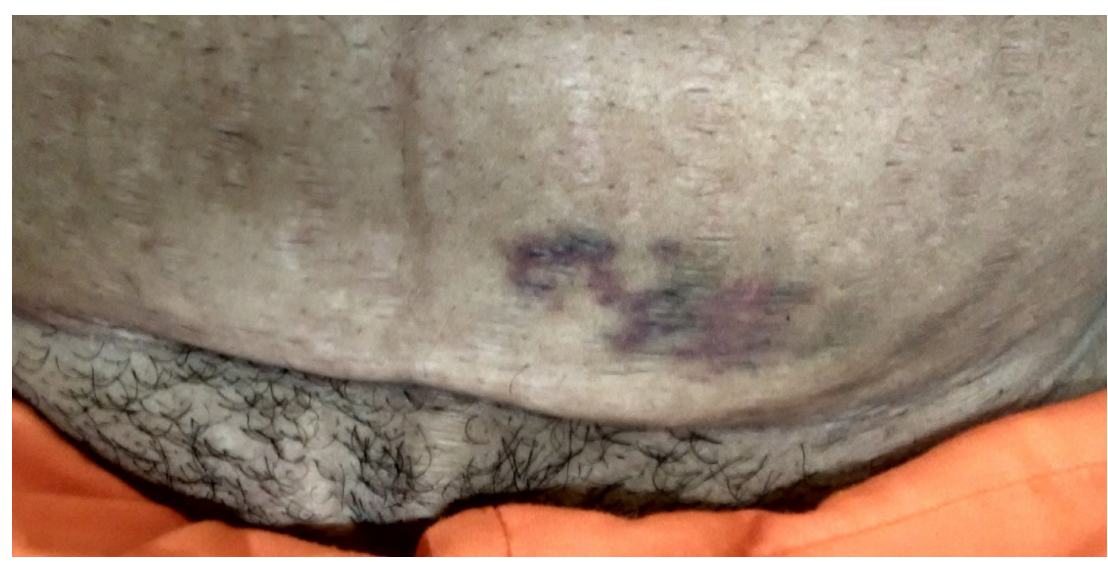

Figure 1: Extravasation of blood in lower abdominal wall

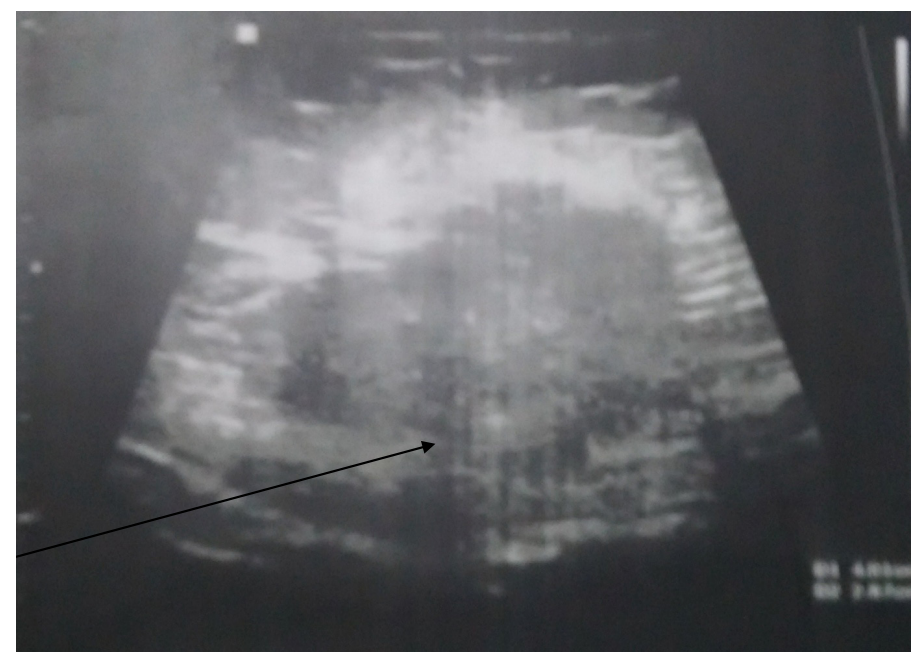

Figure 2: Ultrasound picture of abdominal endometriosis showing rupture

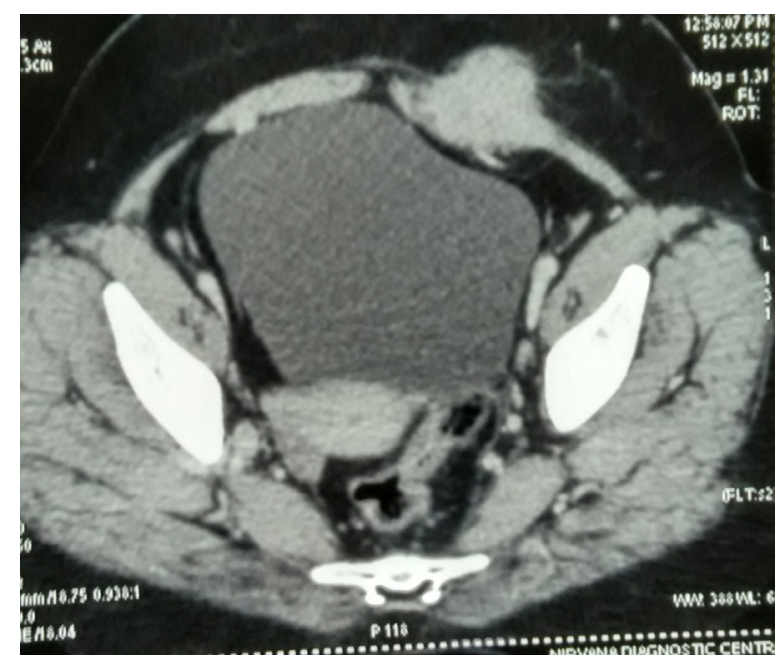

Figure 3: CT picture showing left rectus abdominis muscle endometrioma with extravasation 
After the radiological diagnosis of endometrioma, the fine needle aspiration revealed blood only. The patient was operated under anaesthesia. A transverse incision was given left to umbilicus. The lump was dissected with a safe margin all around excised. The involved anterior abdominal wall muscles and rectus abdominus were excised. The peritoneum was not involved. A large defect was left in the anterior abdominal wall. The polyprolene mesh was used to cover this remnant large abdominal wall defect (Figure 4). The wound was closed with a negative suction drain. The patient remained well in postoperative period and drain was removed on third postoperative day. The wound healed well with infection. The stitches were removed on $10^{\text {th }}$ postoperative day. No recurrence was noted in follow up at 6 months (Figure 5). The excised specimen (Figure 6) and cut section appearances show endometrioma (Figure 7). On histopathological examination confirmed the diagnosis of endometriosis. Microphotograph shows benign endometrial glands and stroma with hemorrhage (Figure 8).

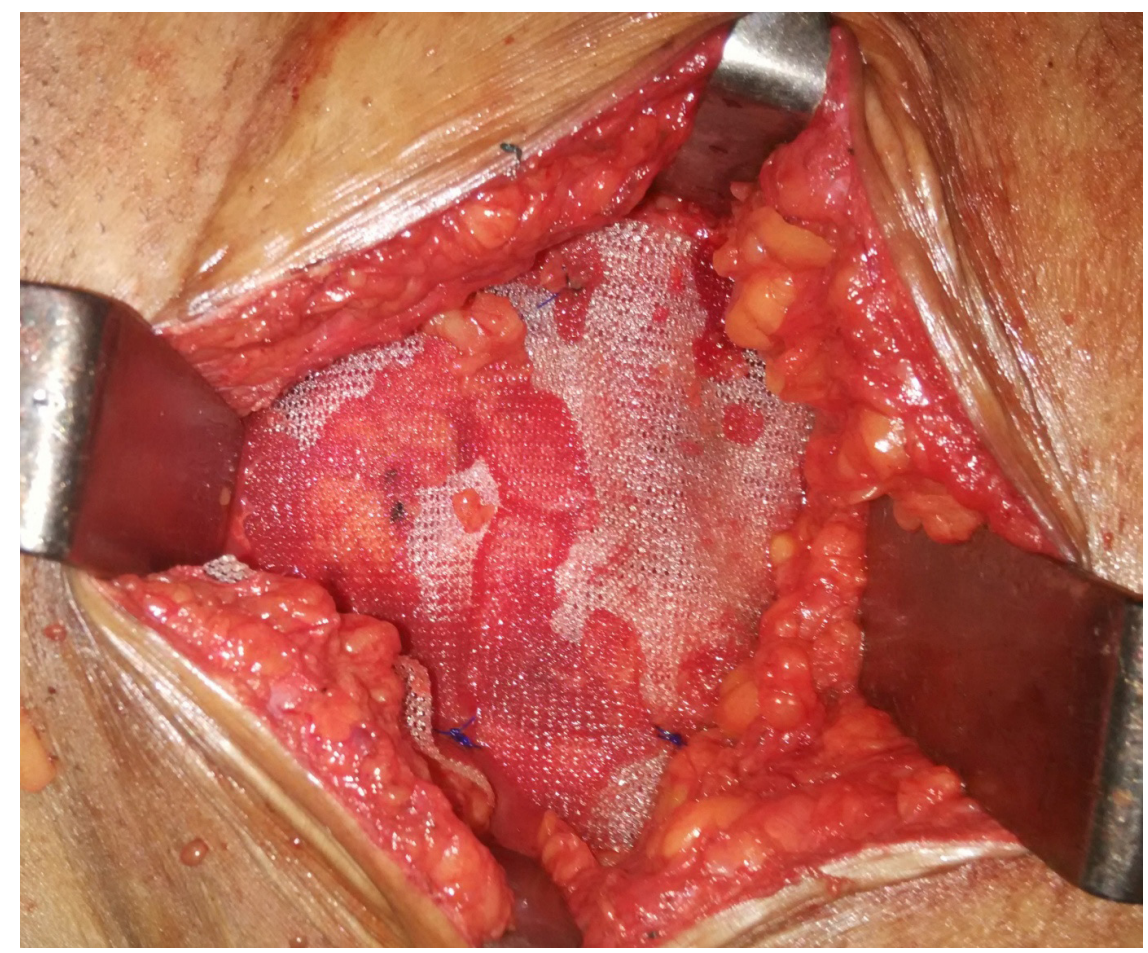

Figure 4: Meshplasty to cover the abdominal wall defect

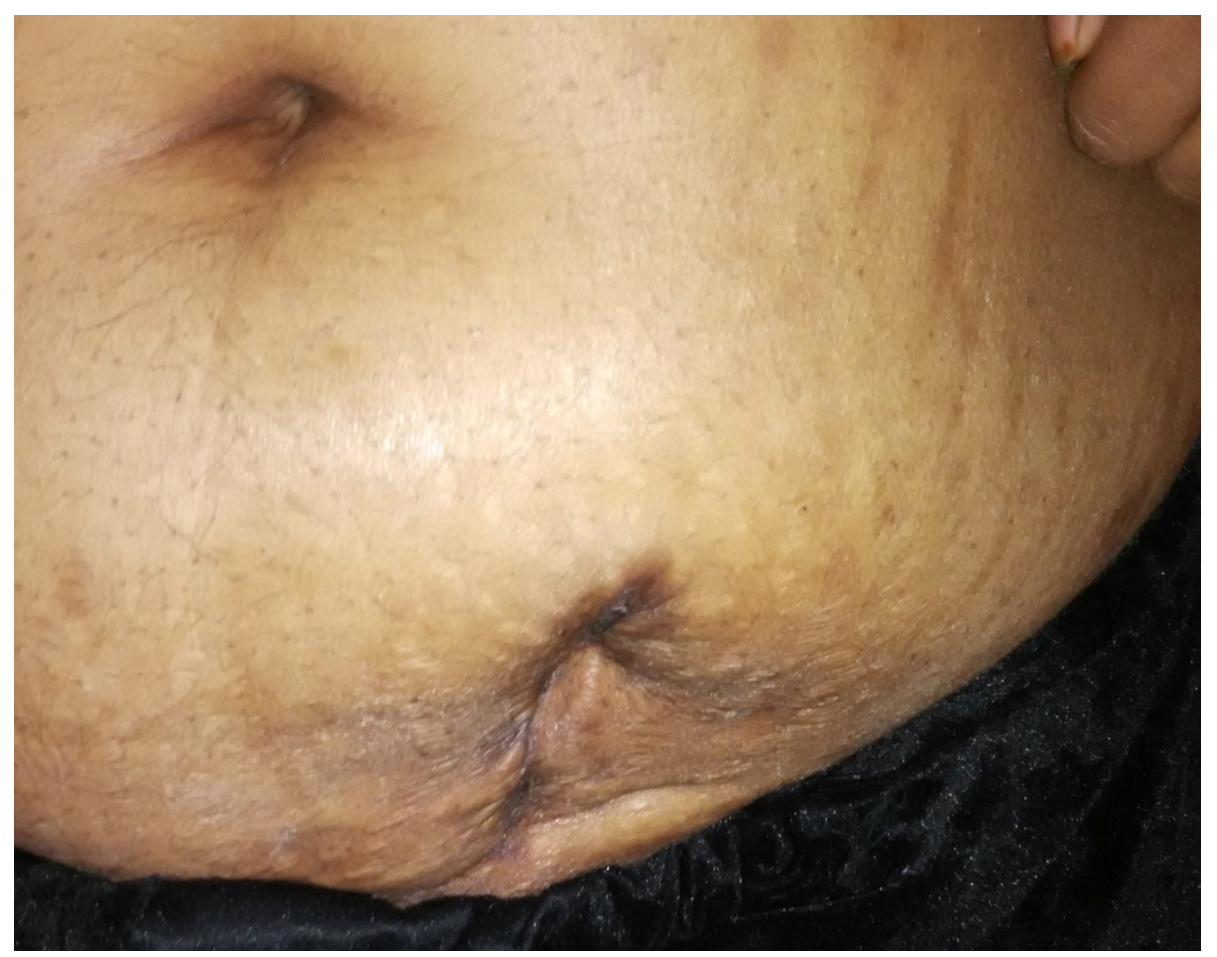

Figure 5: Follow up picture showing no recurrence 


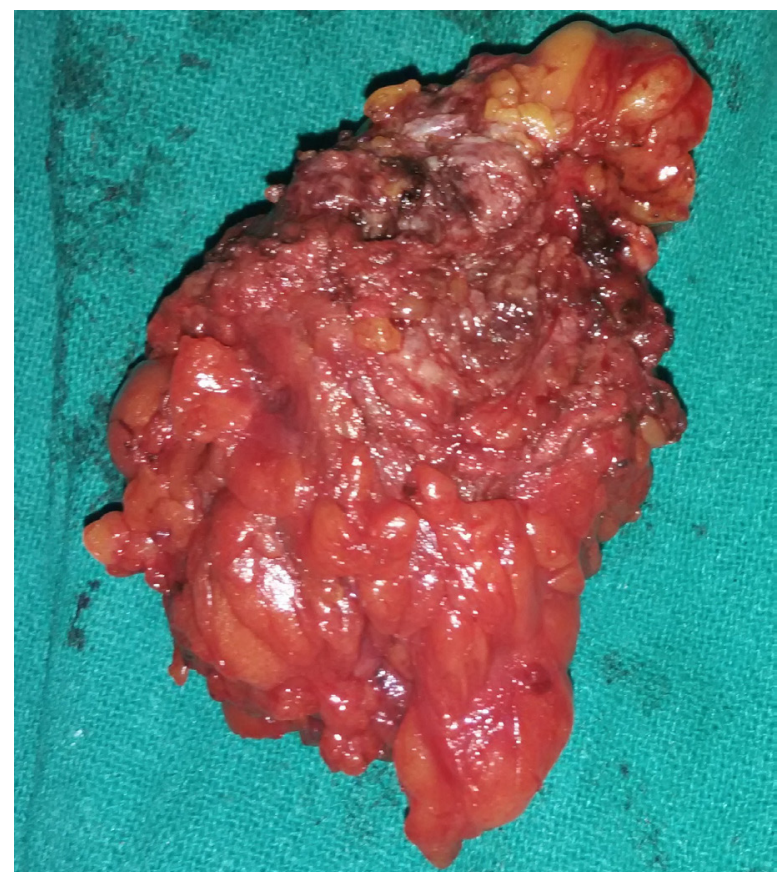

Figure 6: Excised Specimen of Endometrioma

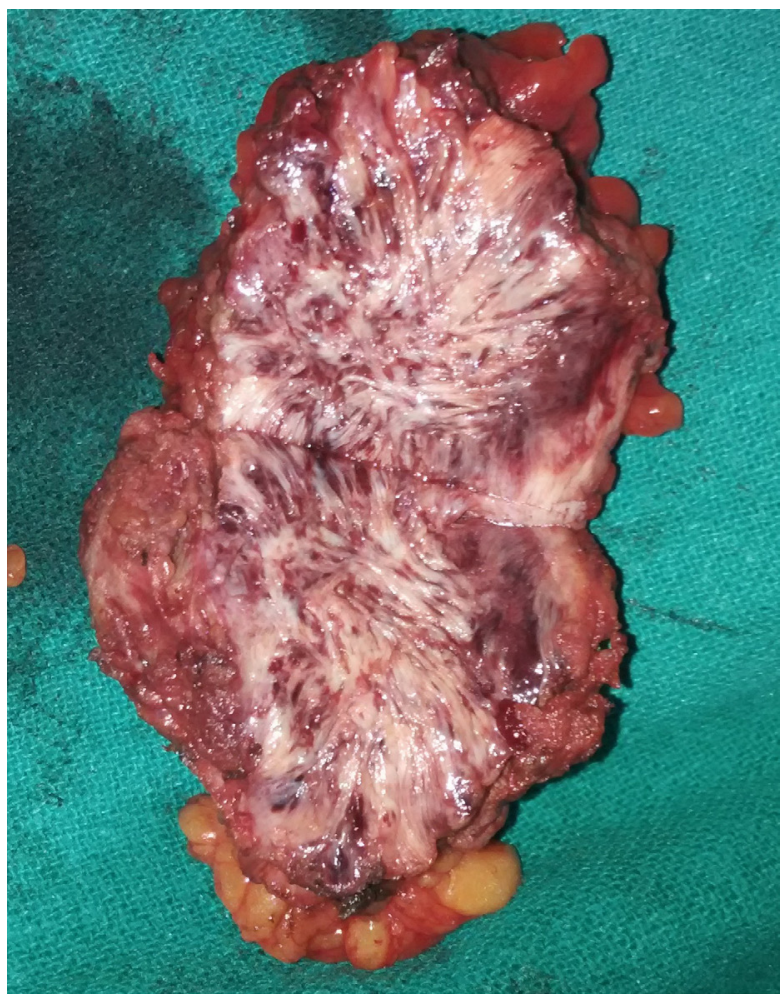

Figure 7: Cut section gross appearance of endometrioma

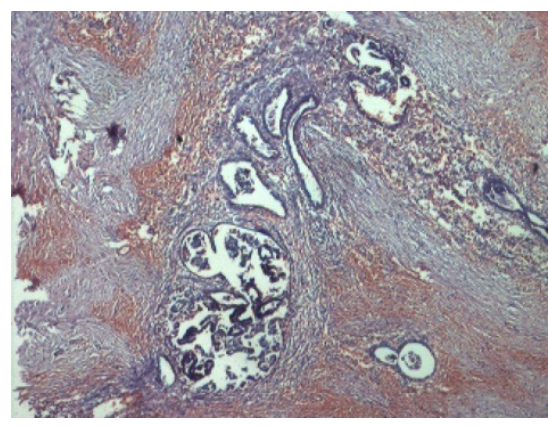

Figure 8: Microphotograph of endometriosis 


\section{Discussion}

First described by Rokitansky in 1860, endometriosis is the presence of ectopic endometrial tissue outside the uterine cavity. Anterior abdominal wall endometriosis although is an uncommon entity but occurs in a scar after obstetrical and gynaecological surgery [10]. Caesarean scar endometriosis is most common among the extrapelvic endometriosis [11]. The incidence of abdominal wall endometriosis is $0.8 \%$ of all women undergoing caesarean section. In abdominal wall endometriosis the skin and subcutaneous tissue is involved more frequently than muscle, fascia, rectus sheath and muscle. In abdominal wall endometriosis muscles of anterior abdominal wall are involved including rectus abdominis muscle [12]. In this case all the muscles including rectus muscle were involved because of giant size. The rectus muscle haematoma, cysticercosis, granuloma, chronic abscess and desmoid tumour should be considered in differential diagnosis.

Yuan et al. studied clinicopathological features of abdominal wall endometriosis in 151 cases with previous caesarean section. The latent period between the previous caesarean section and onset of symptoms was 24 months. However this latent period was not associated with age of patient, type of incision, gestational age, lump size and postpartum menstrual recovery. The size of lump was directly proportional to the size of endometrioma whether more than $3 \mathrm{~cm}$ or less than $3 \mathrm{~cm}$. The time interval between start of symptoms and surgery was 26 months. The size of lesion on preoperative ultrasonography was significantly smaller than size of excised specimen ( $20 \mathrm{~mm}$ versus $35 \mathrm{~mm}$ ). Surgical excision was done in all patients and recurrence rate was $7.8 \%$ while average recurrence rate was $(20 \pm 16)$ months [13]. In another study the clinicopathological features in 151 patients with abdominal wall endometriosis were explored. Most common presentation (80.1\%) was cyclic pain and/or abdominal lump. The latent period was not related to factors such as incision site, gestational age, postpartum menstruation and lactation period [14]. Bektas $\mathrm{H}$ et al. described their 10 years' experience of 40 patients with abdominal wall endometriosis presenting with abdominal mass, cyclic or noncyclic pain. They studied the age, parity, symptoms, diagnostic modalities and current treatment. The duration of symptoms was $18.2 \pm 23.4$ months. The preoperative diagnosis was made in $47.5 \%$ of patients. Recurrence occurred in $9.1 \%$ of cases after surgical excision [15].

The abdominal wall endometrioma is hypothesized to be produced by seedling of endometrial cells during caesarean section. Both endometrial cell and stroma implant during surgery. These implanted cells become viable and start growing. Like uterine endometrium this ectopic tissue is also hormone sensitive. It grows under influence of oestrogen and becomes symptomatic at time of menstruation. The repeated bleeding within this ectopic endometrial tissue and disintegration of blood leads to deposition of haemosiderin. This produces dark brown colour cyst called chocolate cyst. This endometrial cyst is usually multilocular [16]

Preoperative diagnosis can be made using clinical acumen and diagnostic techniques like ultrasound, CT scan and MRI. FNA can provide accurate diagnosis but not in all cases. In this case preoperative diagnosis was made by ultrasound and CT scan. However FNA reported aspiration of blood only. Sonographic findings in abdominal wall endometrioma were hypoechoic solid lesions with cystic changes. For large lesions CT shows well circumscribed lump and for small lesions MRI provides better resolution [17]. In preoperative work up deep infiltrating endometriosis, the results of PET/CT were compared with MRI for distinguishing previous surgical scar and active lesion. PET/CT had greater accuracy than MRI particularly in patients with previous scar [18].

Umbilical endometriosis of anterior abdominal wall is rare entity usually following laparoscopic surgical procedures [19]. But spontaneous umbilical endometriosis without history of any surgery has also been reported [20]. Umbilical endometriosis associated with a large umbilical hernia has also been reported in literature [21].

The anterior abdominal wall endometriosis is conventionally treated by hormone therapy or wide surgical excision. Sclerotherapy can be used for small size abdominal wall endometriosis. In a recent study abdominal wall endometriosis was treated by ultrasound guided ethanol injection hence avoiding the surgery [22]. A preliminary study has reported percutaneous image guided cryoablation of localized symptomatic abdominal scar endometrioma with promising local control [23]. The best option is wide excision should be performed in these patients with post caesarean endometrioma to avoid recurrence. The resultant defect in the anterior abdominal wall may require reconstructed using polypropylene mesh [24]. In a short study robotic single site endometriosis resection using firefly technology with fluorescent Indocyanine Green dye has been done in pelvic endometriosis [25].

The abdominal wall endometrioma can undergo various complications like infection, abscess formation, haemorrhage, rupture and malignant transformation [26]. Endometriosis rupture is very rare complication with only a few cases being reported in literature for pelvic endometrial cyst and anterior abdominal wall endometriosis [27]. This will produce haemorrhage into peritoneum. But no case of haemorrhage and rupture of abdominal wall endometrioma have been found. Endometrioma rupture occurs because of the rapid growth and achieving a giant size. The hormonal stimulation is at peak during the pregnancy. But this patient was not pregnant and rupture occurred during menstruation. The emergency was treated by surgery under antibiotic cover. Gajjar et al. have reported a case of caesarean scar endometriosis presenting as acute abdomen in a 27-year old women. An endometrioma of $2 \mathrm{~cm}$ size near left edge of pfannenstiel incision scar was excised. The tumour like mass was adherent to skin and surrounding subcutaneous tissue. The mass was excised with clear margins from surrounding fat tissue [28]. In the case reported the giant size abdominal wall endometrioma was of $10 \mathrm{x} 11 \mathrm{~cm}$ involving skin, subcutaneous tissue, external oblique, internal oblique, 
transverses abdominis, left rectus muscle and anterior rectus sheath. The peritoneum was not involved. Scar endometriosis is a complication of gynaecological surgery but always treated by general surgeons [29]. These patients are treated by excision with a safety margin and diagnosis confirmed by histopathology. Ucar MG et al. analyzed a series of 12 cases for surgical treatment of scar endometriosis following caesarean section. The size of endometrioma ranged from 2 to $8 \mathrm{~cm}$ in size. Four of these patients had menstruation related enlargement and only one had a complaint of dark brown leakage. Complete wide excision was done in all patients as diagnostic and therapeutic measure. Manipulation during surgery should not spread the endometriosis during surgery [30].

\section{Conclusion}

Post caesarean scar endometriosis should be suspected in diagnosis. An abdominal wall lump with cyclical or noncyclical pain gives the clinical diagnosis of abdominal wall endometriosis. Under hormonal influence it can gain a large size. The complication of rupture and haemorrhage can occur in abdominal wall endometriosis, which is a rare complication of pelvic endometrioma. Wide excision with polypropylene meshplasty under antibiotic cover is the treatment of choice.

\section{References}

1. Ding Y, Zhu J (2013) A retrospective review of abdominal wall endometriosis in Shanghai, China. Int J Gynaecol Obstet 121: 41-4.

2. Mui J, Allaire C, Williams C, Yong PJ (2016) Abdominal wall pain in women with chronic pelvic pain. J Obstet Gynecol Can 38: 154-9.

3. Ozturk A, Kaya C, Bozkurtoglu H, Tan N, Yananli ZD, et al. (2016) Scar endometrioma: An uncommon yet easily treated condition. J Reprod Med 61: 249-53.

4. Tangri MK, Lele P, Bal H, Tewari R, Majhi D (2016) Scar endometriosis: A series of 3 cases. Med J Armed Forces India 72: S185-8.

5. Bennett GL, Slywotzky CM, Cantera M, Hecht EM (2010) Unusual manifestations and complications - Spectrum of imaging findings: Pictorial review. AJR Am J Roentgenol 194: WS34-46.

6. Anand M, Deshmukh SD (2011) Massive abdominal wall endometriosis masquerading as desmoid tumour. J Cutan Aesthet Surg 4: 141-3.

7. Kahlenberg LK, Laskey S (2014) Primary umbilical endometriosis presenting as umbilical drainage in a nulliparous and surgically naive young women. Am J Emerg Med 32: 692 .

8. Hensen JH, Van Breda Vriesman AC, Puylaert JB (2006) Abdominal wall endometriosis: clinical presentation and imaging features with emphasis on sonography. AJR Am J Roentgenol 186: 616-20.

9. Ecker AM, Donnellan NM, Shepherd JP, Lee TT (2014) Abdominal wall endometriosis: 12 years of experience at a large academic institution. Am J Obstet gynecol 211: e1-5.

10. Fahssi ME, Lomdo M, Bounaim A, Ali AA, Sair K (2016) Parietal-scar endometriosis after caesarean section: a rare entity. Pan Afr Med J 24: 79.

11. Miccini M, Gregori M, Ferraro D, Ciardi A, Cassibba S, et al. (2016) Abdominal scar endometriosis: case report. Clin Exp Obstet Gynecol 43: 431-3.

12. Mostafa HA, Saad JH, Nadeem Z, Alharbi F (2013) Rectus abdominis endometriosis. A descriptive analysis of 10 cases concerning this rare occurrence. Saudi Med J 34: 1035-42.

13. Yuan L, Zhang JH, Liu XS (2013) Clinicopathological features of 151 cases with abdominal wall endometriosis. Zhonghua Fu Chan Ke Za Zhi 48: 113-7.

14. Zhang J, Liu X (2016) Clinicopathological features of endometriosis in abdominal wall-clinical analysis of 151 cases. Clin Exp Obstet Gynecol 43: $379-83$.

15. Bektas H, Bilsel Y, Sari YS, Ersoz F, Koc O, et al. (2010) Abdominal wall endometrioma; a 10-year experience and brief review of literature. J Surg Res 164: e77-81.

16. Danielpour PJ, Layke JC, Durie N, Glickman LT (2010) Scar endometriosis - a rare cause for a painful scar: A case report and review of literaure. Can J Plast Surg 18: 19-20.

17. Gidwaney R, Badler RL, Yam BL, Hines JJ, Alexeeva V, et al. (2012) Endometriosis of abdominal and pelvic scars: multimodality imaging findings, pathologic correlation, and radiologic mimics. Radiographics 32: 2031-43.

18. Cosma S, Salgarello M, Ceccaroni M, Gorgoni G, Riboni F, et al. (2016) Accuracy of a new diagnostic tool in deep infiltrating endometriosis: Positron emission tomography-computed tomography with 16a-[18F]fluoro-17ß-estradiol. J Obstet Gynaecol Res 42: 1724-33.

19. Egami S, Kumagai Y, Yokoyama T, Sugiura M (2017) Development of abdominal wall endometriosis in a region distant from a caesarean section scar. Clin Exp Dermatol 10.1111/ced.13018.

20. Calagna G, Perino A, Chianetta D, Vinti D, Triolo MM, et al. (2015) Primary umbilical endometrioma: Analyzing the pathogenisis of endometriosis from an unusual localization. Taiwan J Obstet Gynecol 54: 306-12.

21. Stojanovic M, Radojkovic M, Jeremic L, Zlatic A, Stanojevic G, et al. (2014) Umblical endometriosis associated with large umbilical hernia. Case report. Chirurgia 109: 267-70.

22. Bozkurt M, Cil AS, Bozkurt DK (2014) Intramuscular abdominal wall endometriosis treated by ultrasound-guided ethanol injection. Clin Med Res 12: 160-5.

23. Cornelis F, Petitpierre F, Lasserre AS, Tricaud E, Dallaudiere B, et al. (2014) Percutaneous cryoablation of symptomatic abdominal scar endometrioma: intial reports. Cardiovasc Intervent Radiol 37: 1575-9.

24. Collins AM, Power KT, Gaughan B, Hill AD, Kneafsey B (2009) Abdominal wall reconstruction for a large scar endometrioma. Surgeon 7: 252-3.

25. Guan X, Nguyen MT, Walsh TM, Kelly B (2016) Robotic single-site endometriosis resection using firefly technology. J Minim Invasive Gynecol 23: 10-1.

26. Ramesh B, Chaithra TM, Gupta P, Prasanna G (2016) Anterior abdominal wall scar endometriosis: An enigma. J Obstet Gynaecol India 66: 636-8.

27. Kozawa E, Matsuo Y, Hasegawa K, Fujiwara K, Sakuro T, et al. (2010) Spontaneously ruptured endometrioma associated with endometriod adenocarcinoma: MR findings. Magn Reson Med Sci 9: 233-6.

28. Gajjar KB, Mahendru AA, Khaled MA (2008) Caesarean scar endometriosis presenting as an acute abdomen: a case report and review of literature. Arch Gynecol Obstet 277: 167-9. 
29. Aytac HO, Aytac PC, Parlakgumus HA (2015) Scar endometriosis is a gynaecological complication that general surgeons have to deal with. Clin Exp Obstet Gynecol 42: 292-4.

30. Ucar MG, Sanlikan F, Gocmen A (2015) Surgical treatment of scar endometriosis following caesarean section, a series of 12 cases. Indian J Surg 77: $682-6$.

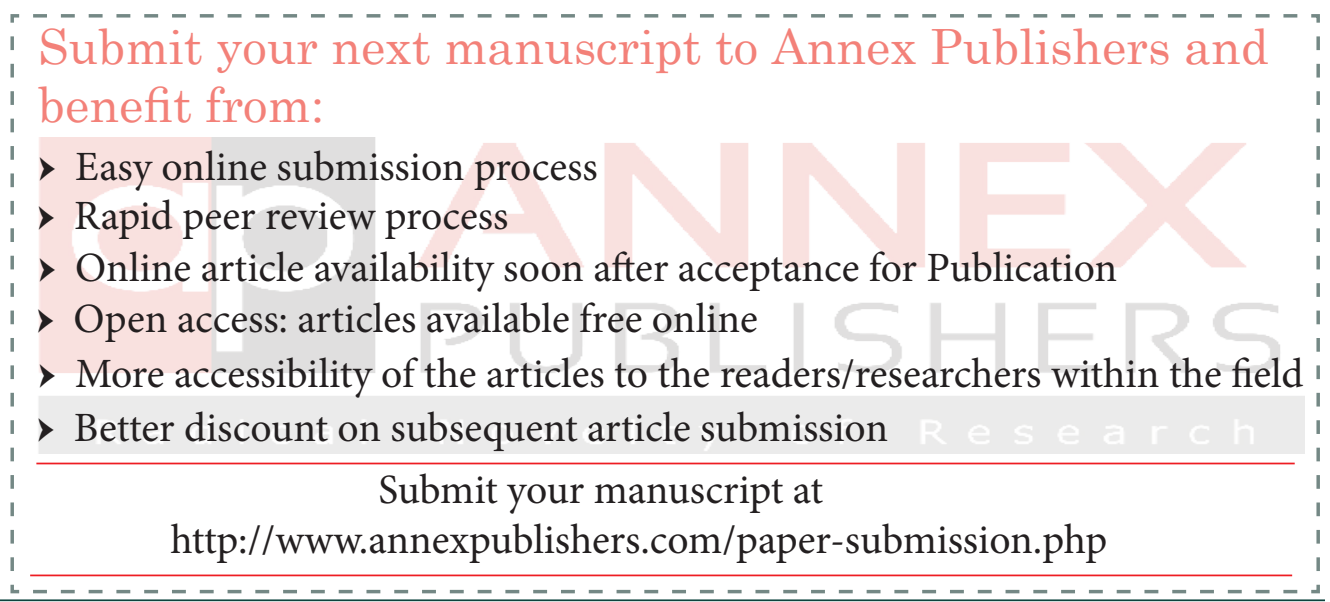

